\title{
«L’Année stendhalienne» 16
}

\section{Michel Arrous}

\section{(2) OpenEdition}

\section{Journals}

\section{Édition électronique}

URL : http://journals.openedition.org/studifrancesi/15538

DOI : 10.4000/studifrancesi. 15538

ISSN : 2427-5856

\section{Éditeur}

Rosenberg \& Sellier

\section{Édition imprimée}

Date de publication : 1 décembre 2018

Pagination : 503-504

ISSN : 0039-2944

\section{Référence électronique}

Michel Arrous, « «L'Année stendhalienne» 16 », Studi Francesi [En ligne], 186 (LXII | III) | 2018, mis en ligne le 01 janvier 2019, consulté le 06 janvier 2021. URL : http://journals.openedition.org/ studifrancesi/15538; DOI : https://doi.org/10.4000/studifrancesi.15538

Ce document a été généré automatiquement le 6 janvier 2021.

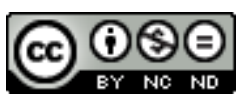

Studi Francesi è distribuita con Licenza Creative Commons Attribuzione - Non commerciale - Non opere derivate 4.0 Internazionale. 


\title{
«L’Année stendhalienne» 16
}

\author{
Michel Arrous
}

\section{RÉFÉRENCE}

«L'Année stendhalienne» 16, Paris, Honoré Champion, 2017, 454 pp.

1 La première partie de cette livraison est consacrée à «Stendhal et la critique», autrement dit à un territoire rarement parcouru. Mécontent de la boutique littéraire, Stendhal imagina en 1822 L'Aristarque, une publication qui rendrait compte objectivement de toute la littérature. Cette ambition d'impartialité, sans doute démesurée, Philippe BERTHIER la montre à l'œuvre dans les contributions à la presse anglaise (Critique et éthique ou le rêve d'Aristarque, pp.15-27). Pour sa part, Yves ANSEL (Défense et illustration de la "critique des créateurs»: le cas de Stendhal, pp. 29-45), suit Stendhal dans sa pratique d'une originale critique de créateur puisqu'il transforme les textes au lieu de les interpréter. Excepté Sainte-Beuve, un des premiers à souligner l'importance de Stendhal critique (tout en se méprenant sur Stendhal romancier), l'originalité des doctrines et des jugements littéraires et esthétiques de Stendhal fut ignorée de ses contemporains. Brigitte DIAZ le rappelle opportunément avec Stendhal critique, un «excitateur d'idées» (pp. 47-69). Après avoir admiré au temps de sa formation La Harpe et les théoriciens du beau idéal, le romanticiste fera le procès de la critique académique française en adoptant une posture d'observateur vigilant qui se livre à une "critique de bonne foi», alors que règne le charlatanisme. Comme l'essentiel de cette œuvre critique date des années 1820, François vanOOSTHUYSE repère quelques traits caractéristiques dans la position excentrique et l'écriture du correspondant parisien des revues anglaises (Le mot d'esprit dans "Paris-Londres", pp. 71-88). Dans sa «chasse aux idiots", Stendhal observe la scène littéraire parisienne en pratiquant l'attaque ad hominem, le persiflage voltairien, surtout l'ironie et le paradoxe pour surprendre le lecteur. Mais loin d'être un insolent spécialiste de la critique d'humeur, Stendhal est avant tout un écrivain-critique, ou plutôt un critique qui écrit du point de vue d'un romancier. Xavier BOURDENET met en évidence l'articulation entre critique et création 
romanesque au tournant de 1830 (Critique et création: Stendhal, Walter Scott et "La Princesse de Clèves", pp. 89-114). Dans ce parallèle quelque peu bancal (il n'est quasiment pas question du roman de Mme de La Fayette), Stendhal s'interroge sur les différents types de mimesis et constate que le «mérite historique» auquel il réduit l'œuvre de Scott, oblige à repenser la poétique romanesque. On peut lire son article comme une préface au Rouge, roman du monde contemporain qui s'oppose à la méthode scottienne (voir à ce propos le «projet d'article» adressé à Salvagnoli). Catherine MARIETTE s'est intéressée à Stendhal, critique des romancières de son temps (pp.115-134), c'est-à-dire aux nombreuses lectures que Stendhal fait des romans féminins. À la différence de SainteBeuve dans ses «Portraits de femmes», Stendhal envisage la spécificité de ces auteures (Mmes de Cubières, Laya, de Duras, Cottin, de Souza, de Genlis, Sophie Gay, Hortense Allart) en termes sociaux et formels. Il note aussi l'emprise de la décence et de la pudeur, au détriment parfois de l'ancrage dans la réalité et de la critique de l'ordre social. Philippe LAMmERS aborde un autre versant de l'entreprise critique de Stendhal, cette fois face aux nouveaux historiens et aux débats historiographiques ("Lettres de Paris par le P. N. D. G." Lettres sur l'histoire de France? La critique de l'histoire chez Stendhal et les historiens libéraux, pp. 135-150). S'il souscrit à l'idéal de l'histoire narrative telle que la pratique Thierry, il s'oppose à la posture apolitique de Barante. Se demandant comment on devient critique, Karin GUNDERSEN esquisse bien rapidement $L a$ formation $d u$ goût littéraire (pp. 151-157) à partir des témoignages et commentaires sur les livres et la lecture disséminés dans la Vie de Henry Brulard. Quoique Stendhal critique d'art n'ait pas bonne réputation, Marie-Pierre CHABANNE constate que ses choix de peintres, pas tous mauvais ou déroutants mais souvent mineurs, excluent l'école de David comme la peinture romantique (Le "Salon" de 1824, ou l'ombre du beau moderne, pp.161-179). À l'instar de Thiers qu'il démarque, voire de Delécluze, Stendhal perçoit l'originalité de la jeune génération, d'ailleurs moins soucieuse de vérité, mais une "vérité trop vraie», que de beauté. Stendhal chroniqueur musical, c'est un autre aspect souvent jugé mineur qu'évoque Béatrice DIDIER (pp.183-195): comparées aux articles parus dans d'autres publications, les chroniques que Stendhal consacra entre 1824 et 1826 à $L a$ Donna del lago dans le «Journal de Paris» prouvent qu'il a perçu l'intérêt de l'œuvre, notamment l'orchestration, le rapport entre texte et musique et le rôle de l'interprète (la Pasta). Ce dossier offre donc un portrait nuancé de l'artiste en critique.

2 Les «Varia» regroupent six études dont deux sur Stendhal et les philosophes, trois sur Stendhal intellectuel européen et une quatrième sur ses rapports avec la modernité. Yvette FORMERY, qui a choisi Stendhal et Maine de Biran (pp. 199-214), retrace les rapports de Stendhal avec l'auteur de l'Influence de l'habitude sur la faculté de penser pour répondre à la question: Stendhal connaissait-il Biran? À ce sujet, il n'est pas du tout certain que le «raisonneur insensé» avec lequel Biran discuta le Vendredi saint de 1812 soit Stendhal. Suit Stendhal et "M. Kousin" (pp. 215-278), étude fort documentée dans laquelle JeanCharles AUGENDRE reprend dans le détail les références souvent polémiques à Victor Cousin et à la "philosophie transcendantale», de 1825 à 1830. Renée DÉNIER, dans Stendhal: "Journal d'un voyage à Londres en 1817" (pp. 279-292), reconstitue l'histoire et souligne l'intérêt de ces quelques pages qui rendent compte d'une expérience vécue, rédigées par le mystérieux Schmit (ou Schmidt) van Dorselaer. Jean-Jacques LABIA a choisi trois moments stratégiques dans la vie intellectuelle et créatrice de Stendhal (L'Allemagne-Autriche de Stendhal au fil du temps, d'une topique à l'autre, pp. 293-314). Première topique italianophile en 1817 , année euphorique marquée par le «coup de 
dés» du polémique Rome, Naples et Florence signé d'un pseudonyme germanique; 1806-1809, expérience de l'Allemagne au sens large d'où naîtra Le Rose et le Vert; deuxième topique italo-germanique en 1825 , année du Rameau de Salzbourg. Jérémie DUBoIs expose les implications de la réception italienne de Stendhal (Les Commémorations de Stendhal dans les relations franco-italiennes de 1947 à 1992: diplomatie culturelle, sociabilité universitaire et construction d'un patrimoine transnational, pp. 355-373). Il s'agit de savoir comment les études stendhaliennes, en Italie et en France, ont pu s'interpénétrer et quelle a été leur influence sur la sociabilité scientifique et littéraire des deux pays. Alors que ces relations bilatérales ont été marquées par d'importantes manifestations jusque dans les années 1980-1990, force est de constater que depuis le début des années 1990 le rythme s'est sensiblement relâché. Enfin, un peu à la suite d'Antoine Compagnon, c'est le "patron, maitre et mesure» de vie qu'invoque Claude BOURRINET (Stendhal, anti-moderne, ou contre-moderne?, pp. 315-353). Alors qu'on voit plutôt en lui un moderne anti-moderne, on a droit à un portrait kaléidoscopique d'un moderne intempestif et sans illusions.

3 Figurent dans les «Notes et documents» (pp.377-420) une nouvelle lettre inédite de Stendhal à Salvagnoli, publiée et commentée par François BRONNER; la transcription des notes de Stendhal sur l'exemplaire Tourneux de l'Histoire de la peinture, retrouvé à Nantes par Jean-Louis OUVRARD; trois notules érudites de Jean-Luc BISSET (il est question de Sénécé qui a l'honneur d'assister à son propre enterrement, de M. Leuwen prêt à sacrifier un ami à un bon mot, et d'une expression proverbiale venue de Plutarque); ainsi que la glose par Michel LEGAT d'un propos de Clémentine sur «ces gros mérites qui accompagnent les larges épaules». Bien qu'il n'ait jamais porté de "grosses épaulettes», Stendhal ne manquait pas d'épaules. L'épouse du général Curial confirme qu'il s'est montré aussi performant que les officiers de haut rang! 